\title{
Natural antioxidants of the Jaffna variety of Moringa Oleifera seed oil of Indian origin as compared to other vegetable oils
}

\author{
By A.S. Bhatnagar and A.G. Gopala Krishna
}

\author{
Department of Lipid Science \& Traditional Foods. CSIR-Central Food Technological Research. \\ Institute. Mysore-570020 \\ Corresponding author: aggk_55@yahoo.com
}

\section{RESUMEN}

\begin{abstract}
Antioxidantes naturales de aceites de semillas de Moringa oleifera variedad Jaffna de origen indio en comparación con otros aceites vegetales
\end{abstract}

Las cosechas de Moringa oleifera se cultivan en toda la India por sus nutritivas vainas, sus hojas y sus semillas. Las semillas de $M$. oleifera están dotadas de un buen contenido de aceite $(\sim 39 \%)$ y se asemejan al aceite de oliva debido a su alto contenido de ácido oleico ( $65-75 \%)$. El objetivo del estudio fue evaluar los antioxidantes naturales de aceites crudos de semillas de M. oleifera variedad de Jaffna (MSO). Los antioxidantes naturales como tocoferoles y fenoles asi como esteroles, carotenoides presentes en MSO y su actividad de captación de radicales se midió en comparación con los de aceite crudos de coco desecado (copra) (CNO), de sésamo (SESO), de semilla de niger (NSO), de palma (CPO), de salvado de arroz (RBO) y de cacahuete refinado comercial (GNO). MSO contenía 88 ppm de tocoferoles totales, siendo $\alpha$-tocoferol el mayoritario $(56,2 \mathrm{ppm})$. MSO también contenía 117,9 ppm de fenoles totales siendo el ácido gálico $(48,5$ ppm) el mayoritario. MSO contenía también cantidades importantes de esteroles $(1700,8 \mathrm{ppm})$ y carotenoides (17,9 ppm). MSO mostró un valor de Cl50 de $35,5 \mathrm{mg}$ $\mathrm{mL}^{-1}$. El estudio indica que MSO tiene características antioxidantes mejores que CNO y comparable con las de GNO.

PALABRAS CLAVE: Aceites de semillas de la India Actividad captadora de radicales - Carotenoides totales Esteroles totales - Fenoles - IC50 valor - Moringa oleifera variedad Jaffna - Tocoferoles.

\section{SUMMARY}

Natural antioxidants of the Jaffna variety of Moringa oleifera seed oil of Indian origin as compared to other vegetable oils

The Moringa oleifera crop is grown all over India for its nutritious pods, leaves and seeds. $M$. oleifera seeds are endowed with a high oil content ( $39 \%)$ which resembles olive oil because of its high oleic acid content ( 65-75\%). The objective of the present study was to evaluate the natural antioxidants of crude seed kernel oil from the Jaffna variety of $M$. oleifera (MSO). Natural antioxidants like tocopherols and phenolics as well as minor compounds such as sterols and carotenoids present in MSO and its radical scavenging activity were measured in comparison to dried coconut kernel (copra) crude oil (CNO), crude sesame oil (SESO), crude niger seed oil (NSO), crude palm oil (CPO), crude rice bran oil (RBO) and commercially refined groundnut oil
(GNO). MSO contained $88 \mathrm{ppm}$ of total tocopherols with $\alpha$ tocopherol (56.2 ppm) being the major tocopherol. MSO also contained $117.9 \mathrm{ppm}$ of total phenolics with gallic acid (48.5 ppm) being the major phenolic. MSO contained fair amounts of sterols (1700.8 ppm) and carotenoids (17.9 ppm). MSO showed an $\mathrm{IC}_{50}$ value of $35.5 \mathrm{mg} \mathrm{mL}^{-1}$. This study indicates that MSO has antioxidant characteristics which are better than CNO and comparable to those of GNO.

KEY-WORDS: $I C_{50}$ value - Indian seed oil - Moringa oleifera Jaffna variety - Phenolics - Radical scavenging activity - Tocopherols - Total carotenoids - Total sterols.

\section{INTRODUCTION}

Moringa oleifera is a pan-tropical species and the most widely cultivated species of a monogeneric family, Moringaceae, which is native to the sub-Himalayan tracts of India, Pakistan, Bangladesh and Afghanistan. The M. oleifera tree is also known as the horseradish tree, drumstick tree, kelor, marango, mlonge, moonga, mulangay, nébéday, saijhan, sajna or Ben oil tree (Sengupta and Gupta, 1970; Ramachandran et al., 1980). $M$. oleifera is an important vegetable crop and minor oil seed crop in India, however, since there is no organized cultivation of moringa crops, its production quantities are not documented. Other countries which cultivate and use moringa crops are Pakistan, Bangladesh, Malaysia, Indonesia, Ethiopia, Philippines, Sudan, West, East and South Africa, tropical Asia, Latin America, the Caribbean, Florida and the Pacific Islands (Sengupta and Gupta, 1970; Ramachandran et al., 1980). The common varieties available in India like Jaffna, Chauakacheri Murunga, Palmurungai and Periyakulam 1 are all used as vegetables. The pods, leaves and seeds of these moringa varieties are used for various culinary preparations.

Moringa seeds are endowed with high oil contents (35-40\%) and are rich source of omega- 9 fatty acids i.e. oleic acid; however, they are underutilized as an oil source (Anwar et al., 2007; Fahey, 2005). There are some reports on the composition and characteristics of $M$. oleifera seed oil varieties from different countries of origin, e.g., India (Lalas and Tsaknis, 2002; Ogunsina et 
al., 2011), Kenya (Tsaknis et al., 1999), Malaysia (Abdulkarim et al., 2005), Pakistan (Anwar et al., 2006; Manzoor et al., 2007; Latif and Anwar, 2008), and Bangladesh (Rahman et al., 2009) which examine its prospect as an alternative vegetable oil source.

Earlier, in our laboratory, we carried out the work on the quality and stability characteristics of crude seed oil from the Indian $M$. oleifera Jaffna variety (Ogunsina et al., 2011). We have reported the physico-chemical characteristics of cold pressed and hexane extracted crude seed oil from the Indian $M$. oleifera Jaffna variety such as color in 1' cell (36.0 Lovibond units), refractive index (1.47), density at $25^{\circ} \mathrm{C}\left(0.92 \mathrm{~g} \mathrm{~mL}^{-1}\right)$, specific gravity (0.90), viscosity (43.6 mPa.s), iodine value $\left(68.5 \mathrm{~g} \mathrm{I}_{2} 100 \mathrm{~g}^{-1}\right)$, saponifation value $(191.2 \mathrm{mg}$

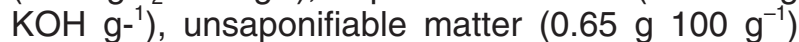
and total tocopherols (90.2 ppm). We also reported its fatty acid composition which showed oleic acid to the extent of $79 \%$ and polyunsaturated fatty acids (PUFA) to the extent of $2 \%$. However, apart from physico-chemical characteristics, the quality of oil also depends on its inherent natural antioxidants such as tocopherols, phenolics, sterols and carotenoids which were not reported in the earlier study (Ogunsina et al., 2011). Hence, in continuation with the previous work, the inherent natural antioxidants of crude seed oil from the Indian $M$. oleifera Jaffna variety are quantified and its radical scavenging ability is reported in this study. Tocopherols, phenolics, sterols and carotenoids are inherent natural antioxidants and bioactive molecules of oil which help in preventing free radical damage to the tissues apart from performing various physiological functions in the body. The natural antioxidants of crude seed oil from the Indian $M$. oleifera Jaffna variety and its radical scavenging activity have not been reported so far. The objective of this study was to evaluate the crude seed oil from $M$. oleifera Jaffna variety for its natural antioxidants and radical scavenging activity in comparison to other common vegetable oils used in India like coconut oil, palm oil, rice bran oil, niger seed oil, sesame oil and groundnut oil.

\section{MATERIALS AND METHODS}

\subsection{Materials}

Dry seeds of the $M$. oleifera Jaffna variety (5 kg) were purchased from the local market of Mysore, Karnataka, India. After dehulling, seed coats $(1.73 \mathrm{~kg})$ and kernels $(3.27 \mathrm{~kg})$ were obtained. The kernels and seed coats comprised $65.4 \%$ and $34.6 \%$, respectively, of the dry seeds of the $M$. oleifera Jaffna variety. Dried coconut kernels (copra), sesame seeds, niger seeds and commercially refined groundnut oil -Goldwinner brand (GNO) were purchased from a local supermarket in Mysore. Rice bran was purchased from a local rice mill in Mysore. Crude palm oil was also purchased from a local palm oil industry in Mysore. Standard $\alpha$-tocopherol, $\gamma$-tocopherol, $\delta$-tocopherol, $\beta$-carotene, cholesterol, gallic acid, caffeic acid, ferulic acid, vanillic acid, cinnamic acid, vanillin, sesamol, sesamin and 2,2-diphenyl-1picryl hydrazyl free radicals (DPPH) were obtained from the Sigma Chemical Co., St. Louis, USA. TertButyl hydro quinone (TBHQ) was obtained from Loba Chemie, Mumbai, India. The other chemicals and reagents used for analysis were of analytical reagent grade.

\subsection{Oil extraction}

The oil extraction from ground moringa kernels was performed according to the Soxhlet extraction method with commercial hexane as the extraction solvent at a ratio of $1: 10$. Briefly, moringa kernels (1 kg) were ground into a fine powder and packed in cellulose extraction thimbles (Whatman). The thimble was placed in the extractor and warm hexane $\left(35-40^{\circ} \mathrm{C}\right)$ was percolated continuously for $8 \mathrm{~h}$ for complete oil extraction. After $8 \mathrm{~h}$ of extraction, miscella was desolventized by flash evaporation and the oil content was determined gravimetrically and expressed as $\mathrm{g} \mathrm{kg}^{-1}$. Similarly, dried coconut kernels (copra), sesame seeds, niger seeds and rice bran, $100 \mathrm{~g}$ each, were ground and packed in cellulose extraction thimbles and the oil was extracted using the Soxhlet extraction method with commercial hexane as the extraction solvent with a material to solvent ratio of 1:10.

\subsection{Unsaponifiable matter of oils}

Unsaponifiable matter of the oil samples was determined according to the AOCS Method No. Ca 6a-40 (Firestone, 1998).

\subsection{Tocopherol determination}

\subsubsection{Total tocopherol determination by spectrophotometry}

The total tocopherol content of the oils was determined according to the IUPAC Method No. 2.301 (Paquot and Havtfenne, 1987).

\subsubsection{Tocopherol analysis by HPLC}

The tocopherol content of the oil was determined according to the AOCS Method No: Ce 8-89 (Firestone, 1998) by normal phase HPLC separation on a silica column (Lichrosorb Si60 pore size $6 \mathrm{~nm}$, pore volume $0.75 \mathrm{~mL} / \mathrm{g}$, particle size $7 \mu \mathrm{m}$, LiChrosorb ${ }^{\circledR}$, Merck Millipore, Merck KGaA, Frankfurter, Darmstadt, Germany) employing Shimadzu HPLC system consisting of an LC-10A pump, injector fitted with $20 \mu \mathrm{L}$ loop and flourescence detector. The mobile phase was hexane: isopropyl alcohol (99.5:0.5, v/v) at the flow rate of $1 \mathrm{~mL} \mathrm{~min}^{-1}$. An excitation wave length 
of $290 \mathrm{~nm}$ and emission wavelength of $330 \mathrm{~nm}$ were maintained for the fluorescence detection of all the peaks. Standard $\alpha, \gamma$ and $\delta$ - tocopherols were used as external and internal standards for the identification and quantitation of tocopherols in the samples by comparing the peak retention times and peak areas of the standard compounds with those of the samples. The tocopherol content in the oil was expressed as ppm.

\subsection{Phenolic compounds}

\subsubsection{Phenolic compounds extraction}

The phenolic compounds were extracted from the oil samples using liquid-liquid extraction according to Taga et al., 1984 with minor modifications. Twenty grams of oil were dissolved in $50 \mathrm{~mL}$ hexane and extracted three times with $30 \mathrm{~mL}$ of methanol/water $(80: 20, \mathrm{v} / \mathrm{v})$. The extracts were pooled and the volume made up to $100 \mathrm{ml}$ with methanol/water $(80: 20, v / v)$ and then used for spectrophotometric and HPLC analyses.

\subsubsection{Total phenolic compound analysis by spectrophotometry}

The concentration of total phenols in the methanolic extract of the oils was estimated with the Folin-Ciocalteau reagent. A sample aliquot of $100 \mu \mathrm{L}$ was added to $900 \mu \mathrm{L}$ of distilled water and $0.5 \mathrm{~mL}$ of Folin- Ciocalteau reagent were added, mixed and kept for $3 \mathrm{~min}$. After $3 \mathrm{~min}, 1 \mathrm{~mL}$ of $15 \% \quad \mathrm{Na}_{2} \mathrm{CO}_{3}$ solution was added; the contents were mixed and the volume made up to $10 \mathrm{ml}$ with distilled water. After 45 min of incubation at room temperature, the absorbance was measured at $750 \mathrm{~nm}$ against the reagent blank. Gallic acid was used as the standard for preparing the calibration curve (0.05-0.4 $\left.\mathrm{mg} \mathrm{mL}^{-1}\right)$. The sample absorbance was interpolated on the standard graph and the total phenolic compounds (such as gallic acid) were calculated and expressed as ppm.

\subsubsection{Phenolic compounds analysis by HPLC}

HPLC analysis of the phenolic compounds in oil samples was done according to Siger et al., 2008. Individual phenolic compounds were separated on a RP-C18 column $(250 \mathrm{~mm} \times 4.5 \mathrm{~mm})$ connected to a high-performance liquid chromatograph (LC 10 A, Shimadzu, Kyoto, Japan) fitted with a $20 \mu \mathrm{L}$ injector loop and UV detector. The gradient mobile phase consisted of solvent $A$ - methanol and solvent $B-2.5 \%$ acetic acid in water (v/v) with the flow rate at $1 \mathrm{~mL} \mathrm{~min}^{-1}$. The dried samples were diluted with methanol/water $(60: 40, \mathrm{v} / \mathrm{v})$ to a concentration of $1 \mathrm{mg} \mathrm{mL}^{-1}$ and $20 \mu \mathrm{L}$ were injected into the injector loop. The phenolic compounds in the samples and the standards were detected at $280 \mathrm{~nm}$ (for hydroxybenzoic acid derivatives i.e. gallic acid, vanillic acid, vanillin) and $320 \mathrm{~nm}$ (for hydroxycinnamic acid derivatives i.e. caffeic, cinnamic, ferulic acids) at $25^{\circ} \mathrm{C}$. The identification was carried out by comparing the peak retention times of oil samples with those of standard compounds. The amount of individual phenolic compounds in the oils was determined using external and internal standards of the individual phenolic compounds and expressed as ppm.

\subsection{Total carotenoid determination by spectrophotometry}

The total carotenoid contents of the oils were determined according to the method of Dauqan et al., 2011 with minor modifications. Oil samples (100 mg) were weighed and diluted with $10 \mathrm{~mL}$ acetone, mixed well by vortexing and read at 446 nm (UV-1601, UV visible spectrophotometer, Shimadzu Corporation, Koyoto, Japan) against a blank of pure acetone. Standard $\beta$-carotene in acetone $\left(1 \mathrm{mg} \mathrm{mL}^{-1}\right)$ solution was prepared and its five aliquots $(0.5-2.5 \mathrm{~mL})$ were read at $446 \mathrm{~nm}$ and a standard $\beta$-carotene curve was generated by plotting the absorbance of $\beta$-carotene against the amount of $\beta$-carotene $(\mu \mathrm{g})$. The sample absorbance was interpolated on the standard graph and the total carotenoid content (as $\beta$-carotene) were calculated and expressed as ppm.

\subsection{Total sterol determination by spectrophotometry}

The total sterol contents of the oils were determined following the Liberman-Burchard method according to Sabir et al. 2003. The oil samples $(1 \mathrm{~g})$ were weighed and diluted with $10 \mathrm{~mL}$ chloroform and mixed well by vortexing. Aliquots of $3 \mathrm{~mL}$ were taken and $2 \mathrm{~mL}$ of the LibermanBurchard reagent $(0.5 \mathrm{~mL}$ of sulphuric acid dissolved in $10 \mathrm{~mL}$ of acetic anhydride) were added to them and the final volume was made up to $7 \mathrm{~mL}$ with chloroform. The Liberman-Burchard reagent reacted with the sterol to produce a characteristic green color whose absorbance was read at $640 \mathrm{~nm}$. A standard cholesterol solution $\left(1 \mathrm{mg} \mathrm{mL}^{-1}\right)$ was prepared and its five aliquots of $0.5-2.5 \mathrm{~mL}$ were taken. $2 \mathrm{~mL}$ of Liberman-Burchard reagent were then added and the final volume was made up to $7 \mathrm{~mL}$ with chloroform. This mixture was incubated in the dark for 15 minutes and read at $640 \mathrm{~nm}$. A standard cholesterol curve was generated by plotting the absorbance of cholesterol against the amount of cholesterol $(\mu \mathrm{g})$. The sample absorbance was interpolated on the standard graph and the total sterol contents (as cholesterol) was calculated and expressed as ppm.

\subsection{Oryzanol determination in rice bran oil}

The oryzanol content in extracted crude rice bran oil was determined using the spectrophotometric method (Gopala Krishna et al., 2001) by dissolving 
$0.01 \mathrm{~g}$ of the sample in $10 \mathrm{ml}$ of hexane and reading the absorbance at $314 \mathrm{~nm}$ in a $1 \mathrm{~cm}$ cell (double beam uv-visible recording spectrophotometer model UV1601, Shimadzu corporation, Kyoto, Japan). Oryzanol content (mg $100 \mathrm{~g} \mathrm{~g}^{-1}$ ) was calculated using the formula: [(A / W $) \times(100 / 358.9)]$; Where, $A=$ absorbance of the sample, $\mathrm{W}=$ weight of the sample in gram per $100 \mathrm{~mL}, 358.9=\mathrm{E}^{1 \%}{ }_{1 \mathrm{~cm}}$ for oryzanol.

\subsection{Lignans determination in sesame oil}

The lignan content in extracted crude sesame oil was determined according to Kamal Eldin and Appelqvist, 1994. The analysis of lignans was performed with HPLC (model LC-10A VP Shimadzu corporation, Kyoto, Japan) equipped with uvdetector set at $290 \mathrm{~nm}$ and a C18 phenomenex column (250 mm length $\times 4.6 \mathrm{~mm}$ i.d.) using $70 \%$ methanol as the mobile phase at a flow rate of $1 \mathrm{~mL} \mathrm{~min}^{-1}$. Standard sesamol and sesamin were used for the quantification of lignans in the sesame oil samples by comparing the retention times and peak area of the standard compounds with those of the oil samples. The total lignan content of sesame oil was also determined according to the spectrophotometry method as per the published procedure of Bhatnagar et al., 2013.

\subsection{Radical Scavenging Activity (RSA) toward DPPH Radicals in oils and determination of $\mathrm{IC}_{50}$ value}

RSA and the presence of hydrogen donors in the oils were examined by the reduction of DPPH radicals in toluene. A toluenic solution of DPPH radicals was freshly prepared at a concentration of $10^{-4} \mathrm{M}$ according to Bhatnagar et al., 2009. The oil samples $(50 \pm 1 \mathrm{mg})$ were placed in test tubes and a 4-mL aliquot of DPPH toluenic solution was added and vortexed for 20 s at ambient temperature. Against a blank of pure toluene without DPPH radicals, the decrease in the absorption at 515 $\mathrm{nm}$ was measured in a $1-\mathrm{cm}$ quartz cell using a UV-visible spectrophotometer (model UV-1601, Shimadzu Corporation, Kyoto, Japan) after 1, 30 and 60 min of mixing. The RSA toward DPPH radicals was estimated from the differences in the absorbance of the toluenic DPPH solution with or without the sample (control). The inhibition percent was calculated using the following equation: Percentage Inhibition = [absorbance of controlabsorbance of test sample)/absorbance of control] $X$ 100. The $\mathrm{IC}_{50}$ value of the oils, expressed as $\mathrm{mg}$ $\mathrm{mL}^{-1}$, denotes the concentration of oil in the DPPH toluenic solution required to cause a $50 \%$ inhibition of DPPH radicals. $5-50 \mathrm{mg}$ of oil samples were taken and a 1-mL aliquot of DPPH toluenic solution was added. The reaction mixture was incubated in the dark for 15 minutes and the absorbance was measured at $515 \mathrm{~nm}$ in a $1-\mathrm{cm}$ quartz cell. A graph was plotted for percent DPPH remaining against the concentration of oil in the DPPH toluenic solution (mg mL $\mathrm{m}^{-1}$ ) and the $\mathrm{IC}_{50}$ value was determined from the interpolation of values on the graph.

\subsection{Statistical analysis}

All oil extractions were performed in duplicate and estimations carried out in triplicate making six determinations $(n=6)$ and the mean \pm standard deviation values are reported. The data were analyzed using the statistical program, GraphPad InStat Demo- [DATASET1.ISD] (Graphpad InStat, 2012). The two-tailed $p$ value was determined to show the significant differences. A significant difference was considered only when the $p$ value $\leq 0.05$.

\section{RESULTS AND DISCUSSION}

\subsection{Oil content, unsaponifiable matter and natural antioxidants}

The oil content of $M$. oleifera Jaffna variety seed kernels was found to be $392.2 \mathrm{~g} \mathrm{~kg}^{-1}$ (Table 1). This agreed well with our previous literature report of $394 \mathrm{~g} \mathrm{~kg}^{-1}$ by Ogunsina et al., (2011) and $383 \mathrm{~g} \mathrm{~kg}^{-1}$ by Lalas and Tsaknis (2002) on Indian M. Oleifera varieties Jaffna and Periyakulam-1, respectively. The oil contents of dried coconut kernels (copra), rice bran, niger seeds and sesame seeds were found to be in the range of $177.2-647.4 \mathrm{~g} \mathrm{~kg}^{-1}$ (Table 1). The results indicate that copra is the richest source of oil followed by sesame, niger, moringa and rice bran. In comparison to $M$. Oleifera, copra and sesame were found to be $1.6 \mathrm{X}$ and $1.4 \mathrm{X}$ richer while niger seed was almost equal in oil content. However, M. Oleifera was richer in oil content than rice bran by $2.2 \mathrm{X}$. The refining of oil removes its inherent natural antioxidants thus bringing down the unsaponifiable matter of the oil to a large extent. M. Oleifera Jaffna variety seed kernel oil (MSO) studied in the present work was of crude (unrefined) nature; hence it has been compared with other crude (unrefined) vegetable oils. The unsaponifiable matter of MSO was found to be $6.5 \mathrm{~g} \mathrm{~kg}^{-1}$ (Table 1). The unsaponifiable matter of CNO, CPO, RBO, NSO and SESO was found to be in the range of 1.9-57.4 $\mathrm{g} \mathrm{kg}^{-1}$ (Table 1). The results suggest that RBO contains the highest amount of unsaponifiable matter followed by SESO, NSO, MSO, CPO and CNO. The natural antioxidants of oil such as sterols, tocopherols, phenolics and carotenoids are present as the unsaponfiable matter of oil (Christie, 2012) hence oil with more abundant amounts of unsaponifiable matter would have higher quantities of these natural antioxidants. The total sterol contents of the oils were found to be in the range of 811.7-9787.5 ppm in the order of decreasing prevalence of $\mathrm{RBO}>\mathrm{SESO}>\mathrm{MSO}>\mathrm{NSO}>\mathrm{CNO}>$ $\mathrm{CPO}$ with $\mathrm{RBO}$ containing the highest and $\mathrm{CPO}$ the lowest amount of sterols while MSO had 1700.8 ppm of sterols (Table 1). The total tocopherol contents of the oils were found to be in the range of 32.5- 
Table 1

Oil, unsaponifiable matter and natural antioxidant contents of different oil crops

\begin{tabular}{ccccccc}
\hline Parameters & $\begin{array}{c}\text { M. Oleifera } \\
\text { Jaffna variety } \\
\text { seed kernel }\end{array}$ & $\begin{array}{c}\text { Dried Coconut } \\
\text { kernel (copra) }\end{array}$ & Palm & Rice bran & Niger seeds & $\begin{array}{c}\text { Sesame } \\
\text { seeds }\end{array}$ \\
\hline $\mathrm{O} \mathrm{C}^{1}$ & $392.2 \pm 1.9^{\mathrm{a}}$ & $647.4 \pm 3.5^{\mathrm{b}}$ & $\mathrm{ND}$ & $177.2 \pm 2.0^{\mathrm{c}}$ & $392.6 \pm 1.6^{\mathrm{a}}$ & $541.5 \pm 2.2^{\mathrm{d}}$ \\
$\mathrm{USM}^{2}$ & $6.5 \pm 0.8^{\mathrm{a}}$ & $1.9 \pm 0.2^{\mathrm{b}}$ & $5.7 \pm 0.9^{\mathrm{a}}$ & $57.4 \pm 3.0^{\mathrm{c}}$ & $13.3 \pm 1.5^{\mathrm{d}}$ & $18.4 \pm 1.0^{\mathrm{e}}$ \\
$\mathrm{T} \mathrm{T}^{3}$ & $88.0 \pm 3.0^{\mathrm{a}}$ & $32.5 \pm 0.5^{\mathrm{b}}$ & $796.8 \pm 14.2^{\mathrm{c}}$ & $1350.6 \pm 20.5^{\mathrm{d}}$ & $184.6 \pm 4.7^{\mathrm{e}}$ & $562.5 \pm 7.3^{\mathrm{f}}$ \\
$\mathrm{T} \mathrm{S}^{4}$ & $1700.8 \pm 15.5^{\mathrm{a}}$ & $896.4 \pm 12.5^{\mathrm{b}}$ & $811.7 \pm 22.8^{\mathrm{c}}$ & $9787.5 \pm 52.6^{\mathrm{d}}$ & $1351.4 \pm 6.0^{\mathrm{e}}$ & $7909.6 \pm 11.4^{\dagger}$ \\
$\mathrm{T} \mathrm{P}^{5}$ & $118.9 \pm 3.9^{\mathrm{a}}$ & $56.2 \pm 4.5^{\mathrm{b}}$ & $76.7 \pm 2.8^{\mathrm{c}}$ & ${ }^{\#} 309.3 \pm 5.2^{\mathrm{d}}$ & $264.8 \pm 6.0^{\mathrm{e}}$ & $\$ 278.9 \pm 4.3^{\dagger}$ \\
$\mathrm{T} \mathrm{C}^{6}$ & $16.9 \pm 0.4^{\mathrm{a}}$ & $5.5 \pm 0.5^{\mathrm{b}}$ & $497.8 \pm 3.5^{\mathrm{c}}$ & $211.8 \pm 4.1^{\mathrm{d}}$ & $26.85 \pm 1.4^{\mathrm{e}}$ & $90.3 \pm 5.2^{\dagger}$ \\
$\mathrm{IC}_{50}{ }^{7}$ & $35.5 \pm 0.3^{\mathrm{a}}$ & $57.5 \pm 2.2^{\mathrm{b}}$ & $30.4 \pm 1.8^{\mathrm{c}}$ & $20.5 \pm 1.1^{\mathrm{d}}$ & $32.2 \pm 0.9^{\mathrm{e}}$ & $28.4 \pm 0.6^{\dagger}$ \\
\hline
\end{tabular}

ND-not determined

${ }^{1} \mathrm{O}$ C, Oil content $\left(\mathrm{g} \mathrm{kg}^{-1}\right) ;{ }^{2}$ USM, Unsaponifiable matter of the oil $\left(\mathrm{g} \mathrm{kg}^{-1}\right) ;{ }^{3} \mathrm{~T} \mathrm{~T}$, Total tocopherols in the oil (ppm); ${ }^{4} \mathrm{~T} \mathrm{~S}$, Total sterols in the oil (ppm); ${ }^{5} \mathrm{~T}$ P, Total phenolics in the oil $(\mathrm{ppm}) ;{ }^{6} \mathrm{~T} \mathrm{C}$, Total carotenoids in the oil $(\mathrm{ppm}) ;{ }^{7} \mathrm{IC}_{50}, \mathrm{IC}_{50}$ value of the oil $\left(\mathrm{mg} \mathrm{mL}^{-1}\right)$ Values are means $\pm \operatorname{SD}(n=6)$.

Values given in rows followed by different alphabetic superscripts are significantly different at $p \leq 0.05$

\# Crude rice bran oil contained $19000 \pm 150$ ppm of oryzanol.

${ }^{\$}$ Crude sesame oil contained $10662 \pm 80$ ppm of lignans.

1350.6 ppm in the order of decreasing prevalence of $\mathrm{RBO}>\mathrm{CPO}>\mathrm{SESO} \mathrm{NSO}>\mathrm{MSO}>\mathrm{CNO}$ with RBO containing the highest and CNO the lowest amount of tocopherols while MSO had 88.0 ppm of tocopherols (Table 1). The total phenolic contents of the oils were found to be in the range of 56.0$278.9 \mathrm{ppm}$ in the order of decreasing prevalence of $\mathrm{RBO}>\mathrm{SESO}>\mathrm{NSO}>\mathrm{MSO}>\mathrm{CPO}>\mathrm{CNO}$ with RBO containing the highest and CNO the lowest amount of phenolics while MSO had 118.9 ppm of phenolics (Table 1). The total carotenoid contents of the oils were found to be in the range of 5.5$497.8 \mathrm{ppm}$ in the order of decreasing prevalence of $\mathrm{CPO}>\mathrm{RBO}>\mathrm{SESO}>\mathrm{NSO}>\mathrm{MSO}>\mathrm{CNO}$ with $\mathrm{CPO}$ containing the highest and CNO the lowest amount of carotenoids while MSO had 16.9 ppm of carotenids (Table 1). Apart from tocopherols, sterols, phenolics and carotenoids, RBO and SESO also contained oryzanol (19000 ppm) and lignans (10200 ppm) respectively, both of which have strong antioxidant and bioactive functions (Gopala Krishna et al., 2001; Namiki, 2007). The presence of natural antioxidants plays a vital role in free radical inhibition. The $I_{50}$ values of the oils were found to be in the range of $20.5-57.5 \mathrm{mg} \mathrm{mL}^{-1}$ in the order of increasing prevalence of $\mathrm{RBO}<\mathrm{SESO}<\mathrm{CPO}<$ $\mathrm{NSO}<\mathrm{MSO}<\mathrm{CNO}$ with RBO exhibiting lowest and $\mathrm{CNO}$ the highest $\mathrm{IC}_{50}$ value while MSO showed an $I_{50}$ value of $35.5 \mathrm{mg} \mathrm{mL}^{-1}$ (Table 1). The strong $\mathrm{IC}_{50}$ value of RBO and SESO could also be attributed to the radical scavenging activity of oryzanol and lignans present in them (Bhatnagar et al., 2009).

\subsection{Tocopherols, sterols and carotenoid contents of MSO and GNO}

Tocopherols are benzopyranols or methylated tocols consisting of 20-carbon phytyl tail (including the pyranol ring) attached to the benzene ring. Tocopherols are important minor constituents of vegetable oils which serve as antioxidants to retard oxidative rancidity and as a source of the essential nutrient vitamin-E. They are natural lipid soluble antioxidants and potent free radical scavengers present in the oil (Christie, 2012). The main biochemical function of tocopherols is believed to be the protection of consumed polyunsaturated fatty acids (PUFA) against peroxidation (KamalEldin and Andersson, 1997). MSO contains no linoleic acid and only $2 \%$ linolenic acid (Ogunsina et al., 2011). MSO contained 88 ppm of the total tocopherols. As shown in Table 2, $\alpha$-tocopherol (56.2 ppm) was found to be the major tocopherol in MSO, while $\gamma$-tocopherol (12.6 ppm) and $\delta$-tocopherol (19.2 ppm) were also present. These results agreed well with our previous literature report of 90.2 ppm by Ogunsina et al. (2011) on crude seed oil from the Indian M. oleifera Jaffna variety and $82.6 \mathrm{ppm}$ by Tsaknis et al. (1999) on crude seed oil from the Kenyan $M$. oleifera Mbololo variety. The PUFA content of MSO is only $\sim 2 \%$ which means that MSO contains a surplus of tocopherols for quenching free radicals and performing its other antioxidant functions in the human body. GNO contained significantly higher amounts $(p \leq 0.05)$ of total tocopherols (102 ppm) with $\gamma$-tocopherol (70.5 ppm) being the major tocopherol followed by $\alpha$-tocopherol (26.2 ppm) and $\delta$-tocopherol (5.3 ppm) (Table 2). Sterols or steroid alcohols are a class of organic compounds that contain a common steroid nucleus plus an 8 to 10 carbon side chain and an alcohol group. Phytosterols are known to be effective in lowering low-density lipoprotein-cholesterol levels in humans (Christie, 2012). Sterols are generally present in higher amounts in crude oils than refined oils, as the deodorization step during the refining process removes most of the native sterols present in the oil. MSO, being of unrefined nature, contained significantly higher amounts $(p \leq 0.05)$ of total 
Table 2

Tocopherol, Phenolic, carotenoid, and sterol contents of MSO and GNO

\begin{tabular}{|c|c|c|c|c|}
\hline Parameters & $\begin{array}{c}\text { Indian M. oleifera } \\
\text { Jaffna variety seed } \\
\text { oil (MSO) }\end{array}$ & $\begin{array}{l}\text { Commercially } \\
\text { refined groundnut } \\
\text { oil (GNO) }\end{array}$ & $\begin{array}{l}\text { Indian M. oleifera } \\
\text { Periyakulam } 1 \text { variety } \\
\text { seed oil (Lalas and } \\
\text { Tsaknis, 2002) }\end{array}$ & $\begin{array}{l}\text { Kenya M. oleifera } \\
\text { Mbololo variety seed oil } \\
\text { (Tsaknis et al., 1999) }\end{array}$ \\
\hline$\alpha-T^{1}$ & $56.2 \pm 1.6^{a}$ & $26.2 \pm 1.0^{b}$ & 15.4 & 42.6 \\
\hline$\gamma-\mathrm{T}^{2}$ & $12.6 \pm 0.8^{\mathrm{a}}$ & $70.5 \pm 1.2^{b}$ & 4.5 & 15.8 \\
\hline$\delta-\mathrm{T}^{3}$ & $19.2 \pm 0.6^{\mathrm{a}}$ & $5.3 \pm 0.3^{b}$ & 15.5 & 24.2 \\
\hline $\mathrm{T} \mathrm{T}^{4}$ & $88.0 \pm 3.0^{\mathrm{a}}$ & $102.0 \pm 2.5^{b}$ & 35.4 & 82.6 \\
\hline$G A^{5}$ & $48.5 \pm 1.2^{\mathrm{a}}$ & $20.5 \pm 1.5^{\mathrm{b}}$ & ND & ND \\
\hline$C A^{6}$ & $15.6 \pm 0.7^{\mathrm{a}}$ & $3.6 \pm 0.2^{b}$ & ND & ND \\
\hline $\mathrm{FA}^{7}$ & $13.1 \pm 0.5^{\mathrm{a}}$ & $2.1 \pm 0.3^{b}$ & ND & ND \\
\hline$V A^{8}$ & $12.4 \pm 0.3^{\mathrm{a}}$ & $1.4 \pm 0.2^{b}$ & ND & ND \\
\hline $\mathrm{Cn} \mathrm{A}^{9}$ & $16.8 \pm 0.8^{a}$ & $3.8 \pm 0.4^{b}$ & ND & ND \\
\hline $\mathrm{Vn}^{10}$ & $11.5 \pm 0.4$ & $\mathrm{Nd}$ & ND & ND \\
\hline $\mathrm{T} \mathrm{P}^{11}$ & $118.9 \pm 3.9^{a}$ & $31.4 \pm 2.6^{b}$ & ND & ND \\
\hline $\mathrm{T} \mathrm{C}^{12}$ & $16.9 \pm 0.4^{a}$ & $8.2 \pm 0.2^{b}$ & ND & ND \\
\hline $\mathrm{T} \mathrm{S}^{13}$ & $1700.8 \pm 15.5^{\mathrm{a}}$ & $1153.1 \pm 9.4^{b}$ & 5600 & ND \\
\hline
\end{tabular}

ND-not determined

Nd-not detected

${ }^{1} \alpha-\mathrm{T}$, alpha tocopherol (ppm); ${ }^{2} \gamma-\mathrm{T}$, gamma tocopherol (ppm); ${ }^{3} \delta-\mathrm{T}$, delta tocopherol (ppm); ${ }^{4} \mathrm{~T} \mathrm{~T}$, Total tocopherols (ppm);

${ }^{5} \mathrm{G}$ A, Gallic acid (ppm); ${ }^{6} \mathrm{C}$ A, Caffeic acid (ppm); ${ }^{7} \mathrm{~F}$ A, Ferulic acid (ppm); ${ }^{8} \mathrm{~V}$ A, Vanillic acid (ppm); ${ }^{9} \mathrm{Cn}$ A, Cinnamic acid (ppm);

${ }^{10}$ Vn, Vanillin (ppm); ${ }^{11}$ T P, Total phenolics (ppm); ${ }^{12} \mathrm{~T} \mathrm{C}$, Total carotenoids (ppm); ${ }^{13} \mathrm{~T}$ S, Total sterols (ppm)

Values are means \pm SD $(n=6)$.

Values given in rows followed by different alphabetic superscripts are significantly different at $p \leq 0.05$.

sterols (1700.8 ppm) as compared to GNO which contained $1153.1 \mathrm{ppm}$ of total sterols (Table 2). The total sterol content of MSO was found to be less than the total sterol content (5600 ppm) of crude seed oil from $M$. oleifera Periyakulam-1 variety as reported by Lalas and Tsaknis, 2002 (Table 2). Carotenoids are a class of hydrocarbons consisting of eight isoprenoid units. $\beta$-carotene, lutein, lycopene, zeaxanthin are some of the carotenoids present in vegetable oils (Christie, 2012). Carotenoids also contribute to the color of the oil and are generally present in higher amounts in crude oils than their refined counterparts, as the bleaching step during the refining process destructs major amounts of endogenous carotenoids present in the oil. MSO, being of unrefined nature, contained significantly higher amounts $(p \leq 0.05)$ of total carotenoids (17.9 ppm) as compared to GNO which contained $10.2 \mathrm{ppm}$ of total carotenoids (Table 2). The low carotenoid and sterol contents of GNO might be due to its refined form because refining includes bleaching and deodorization procedures which remove carotenoids and sterols respectively. Cold-pressed oils have better nutritive properties than solvent extracted and refined oils (Siger et al., 2008). Cold pressed MSO, being clear oil with very low amounts of waxes and phospholipids (Ogunsina et al., 2011) may be consumed in unrefined (virgin) form provided the oil is extracted from the seed kernels by cold pressing followed by filtration. This may also improve the bio-availability of natural antioxidants present in MSO to the human body upon consumption.

\subsection{Phenolic contents of MSO and GNO}

Phenolics are a class of chemical compounds consisting of one or more hydroxyl functional groups $(-\mathrm{OH})$ attached to an aromatic hydrocarbon ring (Christie, 2012). Phenolics are also natural lipid soluble antioxidants and potent free radical scavengers present in the oil. Phenolic compounds have great influence on the stability, sensory and nutritional characteristics of the oil and may prevent deterioration through the quenching of free radicals responsible for lipid oxidation. Olive oil is believed to be highly stable because of its large quantity of phenolics (Siger et al., 2008). MSO contained $117.9 \mathrm{ppm}$ of total phenolics with gallic acid (48.5 ppm) being the major phenolic, while caffeic acid (15.6 ppm), ferulic acid (13.1 ppm), vanillic acid (12.4 ppm), cinnamic acid (16.8 ppm), vanillin (11.5 ppm) were also present (Table 2). The present work is probably the first report on the qualitative and quantitative determination of the phenolics of crude seed oil from the Indian $M$. oleifera Jaffna variety. GNO showed significantly lower amounts ( $p \leq 0.05)$ of total phenolics $(31.4 \mathrm{ppm})$ as compared to MSO. Gallic acid (20.5 ppm) was 
found to be the major phenolic in GNO, while caffeic acid (3.6 ppm), ferulic acid (2.1 ppm), vanillic acid (1.4 ppm), cinnamic acid (3.8 ppm) were also present (Table 2). The low phenolic contents of GNO might be due to its refined form as refining includes alkali neutralization and water washing of the oil which removes phenolic acid compounds. As mentioned earlier, the consumption of cold pressed MSO may improve the bio-availability of its endogenous phenolics to the human body.

\subsection{Radical scavenging activity of oils}

Free radicals may cause reversible or irreversible damages to biological molecules such as DNA, proteins and/or lipids. These damages may cause cancer, heart diseases and arthritis, and could accelerate the aging of organisms (Siger et al., 2008). Figure 1 shows the DPPH radical scavenging activity of MSO, GNO and GNO + 200 ppm TBHQ. At the first minute of of the incubation of $\mathrm{MSO}$, GNO and GNO + 200 ppm, TBHQ showed 28, 19 and $63 \%$ inhibition respectively, which steadily increased with time and eventually showed 92, 84 and $99 \%$ inhibition, respectively after sixty minutes of incubation. MSO, being richer in bioactives like tocopherols, phenolics, sterols and carotenoids than GNO, showed significantly higher $(p \leq 0.05)$ percent inhibition of DPPH radicals from the beginning to end of incubation. Since MSO is vastly rich in monounsaturated oleic acid $(\sim 79 \%)$ and very poor in PUFA ( 2\%) (Ogunsina et al., 2011), it contains an excess of antiradical molecules like tocopherols, phenolics and carotenoids for preventing the peroxidation of its PUFA contents and quenching free radicals in the human body.

\section{5. $I_{50}$ value of $M S O$ and GNO}

The $I_{50}$ value of an oil is its concentration which causes $50 \%$ reduction in the total amount of radicals (DPPH) in a solution. Figure 2 shows the $I_{50}$ value of MSO and GNO. MSO at a concentration of 35.5 $\mathrm{mg} \mathrm{mL}^{-1}$ showed a $50 \%$ reduction in DPPH radicals while GNO showed $50 \%$ reduction in DPPH radicals at a concentration of $45.0 \mathrm{mg} \mathrm{mL}^{-1}$. MSO, being rich in bioactives like tocopherols, phenolics, sterols and carotenoids, showed a significantly higher ( $p \leq$ 0.05) $I C_{50}$ value as compared to GNO. GNO, being fairly rich in PUFA ( 31\%) (Bhatnagar et al., 2009) may require most of its natural antioxidants for the prevention of peroxidation of its PUFA content. On the other hand, MSO, being poor in PUFA ( 2\%) (Ogunsina et al., 2011) has higher amounts of natural antioxidants at its disposal for quenching free radicals. This could be the reason for a higher $\mathrm{IC}_{50}$ value of MSO than GNO despite being poorer in tocopherols.

\section{CONCLUSIONS}

The present study indicates that the Indian M. oleifera Jaffna variety seed contains edible oil rich in natural antioxidants. The consumption of this oil may provide health benefits in terms of hypocholesterolemic effects (due to the presence of phytosterols) and scavenging of free radicals in the body (due to the presence of tocopherols, phenolics and carotenoids). The crude seed oil from the Indian $M$. oleifera Jaffna variety, being rich in monounsaturated oleic acid and poor in PUFA contains surplus amounts of natural antioxidants and also exhibits better antiradical activity than

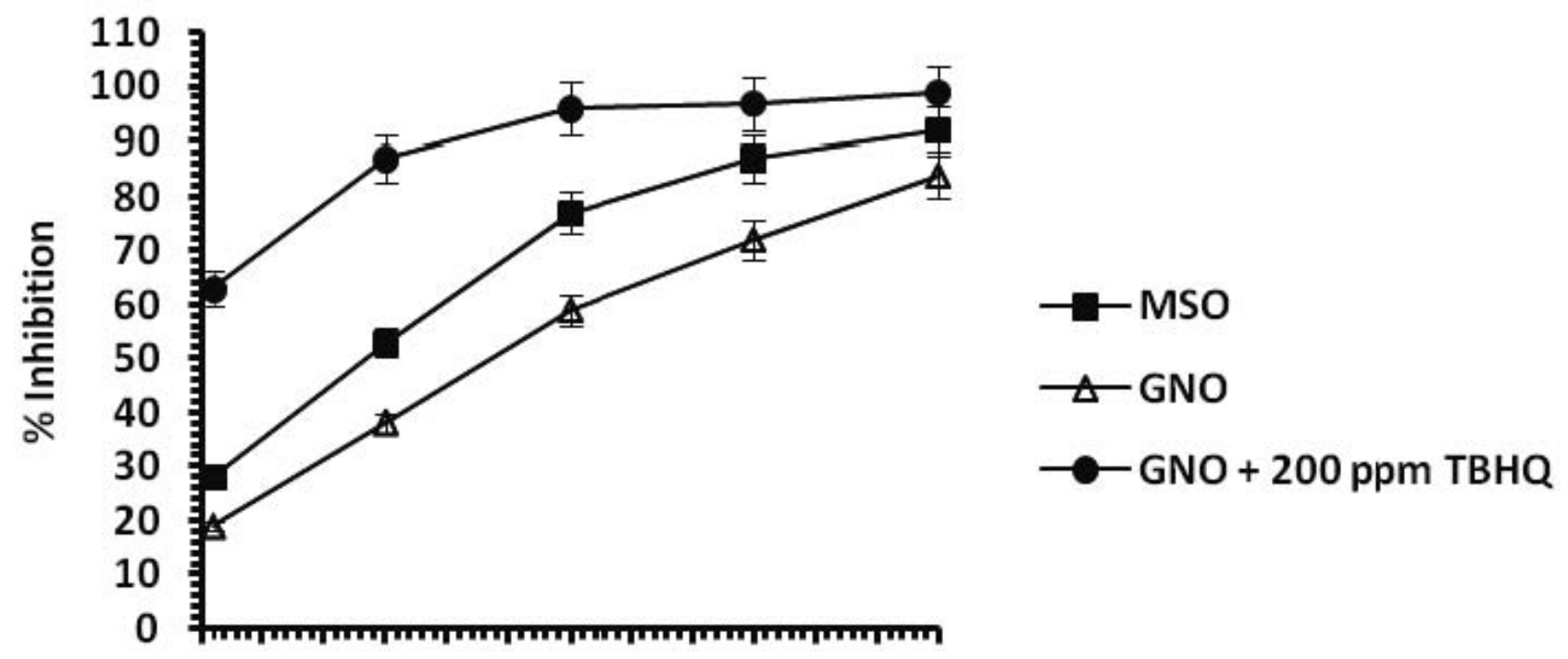

051015202530354045505560

Time (minutes)

Figure 1

DPPH radical scavenging activity of oils. 


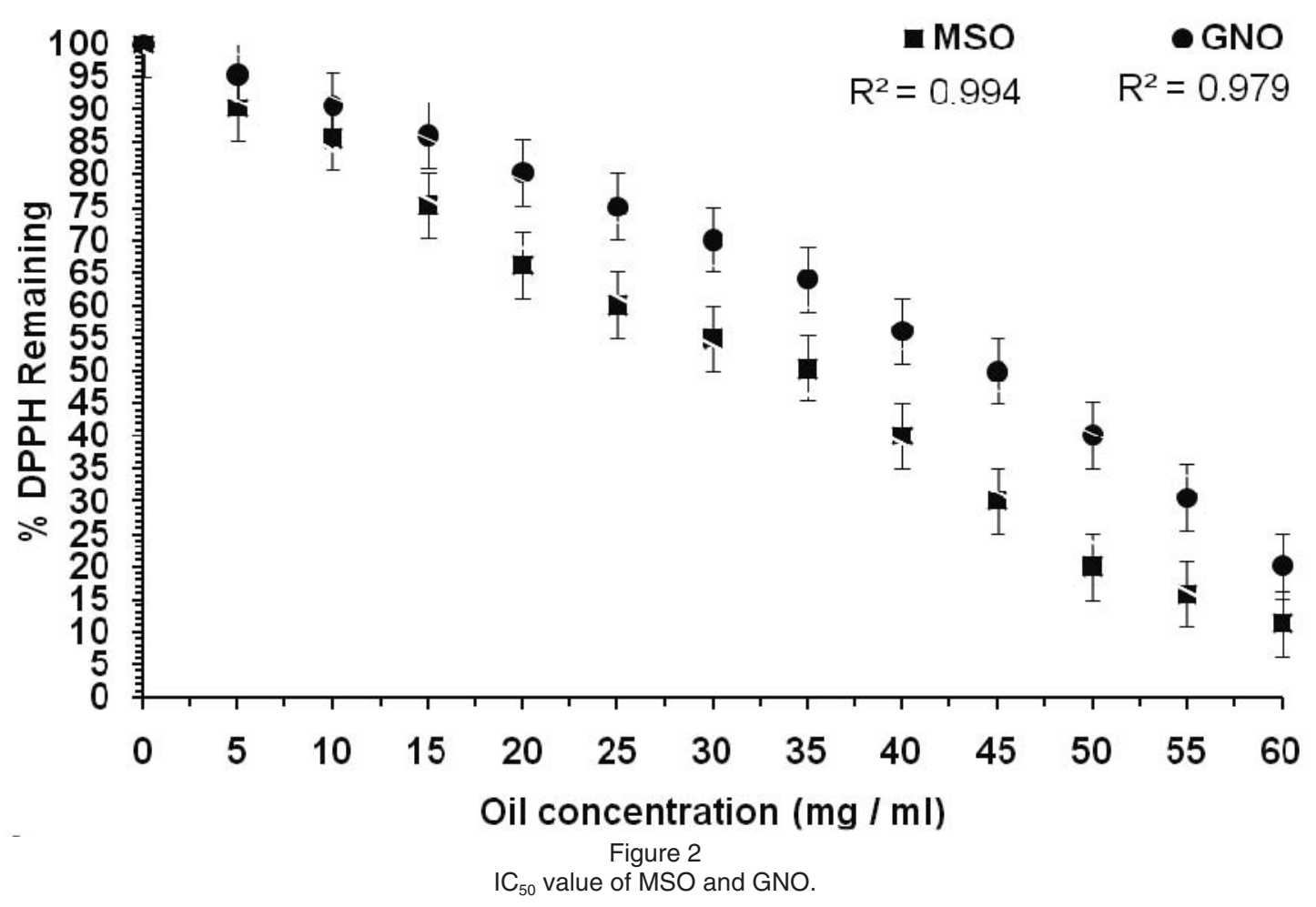

commonly used copra oil and commercially refined groundnut oil. The crude seed oil from the Indian $M$. oleifera Jaffna variety, being rich in monounsaturated oleic acid and poor in PUFA, may also provide better bio-availability of its inherent natural antioxidants to the human body, which may be evaluated through in-vitro/in-vivo studies.

\section{ACKNOWLEDGEMENTS}

The authors wish to thank the Director, CFTRI, Mysore, for providing infrastructural facilities. The authors would like to thank Dr. Babatunde S. Ogunsina, Obafemi Awolowo University, Ile Ife, Nigeria, for taking the initiative for the work on $M$. oleifera seed oil. One of the authors, Ajit Singh Bhatnagar wishes to thank CSIR-Delhi for the grant of Senior Research Fellowship for his Ph.D. program.

\section{REFERENCES}

Abdulkarim SM, Long K, Lai OM, Muhammad SKS, Ghazali HM. 2005. Some physico-chemical properties of Moringa oleifera seed oil extracted using solvent and aqueous enzymatic methods. Food Chem. 93, 253-263.

Anwar F, Syeda NZ, Umer R. 2006. Characterization of Moringa oleifera seed oil from drought and irrigated regions of Punjab, Pakistan. Grasas Aceites 57, 160168.

Anwar F, Latif S, Ashraf M, Gilani AH. 2007. Moringa oleifera: a food plant with multiple bio-chemical and medicinal uses- a review. Phytother. Res. 21, 17-25.

Bhatnagar AS, Hemavathy J, Gopalakrishna AG. 2013. Development of a rapid method for estimation of lignans content in sesame oil. J. Food. Sci. Technol. DOI 10.1007/s13197-013-1012-0.

Bhatnagar AS, Prasanthkumar PK, Hemavathy J, Gopalakrishna AG. 2009. Fatty acid composition, oxidative stability and radical scavenging activity of vegetable oil blends with coconut oil. J. Am. Oil Chem. Soc. 86, 991-999.

Christie WW. 2012. The Lipid Library. http://lipidlibrary. aocs.org/ (Accessed on $20^{\text {th }}$ March 2012).

Dauqan E, Sani HA, Abdullah A, Muhamad H, Top AGM. 2011. Vitamin $E$ and beta carotene composition in four different vegetable oils. Am. J. App. Sci. 8, 407412.

Fahey JW. 2005. Moringa oleifera: A Review of the Medical Evidence for Its Nutritional, Therapeutic, and Prophylactic Properties. Part1. Trees for Life J. 1, 5-20.

Firestone D. 1998. AOCS method No. Ca 6a-40, Ce 8-89. Official methods and recommended practices of the American Oil Chemists Society, 5th Ed. AOCS press, 1608, Broadmoore drive Champaign, Illinois-61826 USA.

Gopala Krishna AG, Khatoon S, Shiela PM, Sarmandal CV, Indira TN, Mishra A. 2001. Effect of refining of crude rice bran oil on the retention of oryzanol in the refined oil. J. Am. Oil Chem. Soc. 78, 127-131.

Graphpad instat demo-[DATASET1.ISD]. 2012. Graphpad Software Inc. 11452, El Camino Real, \#215, San Diego, 92130 USA. www.graphpad.com.

Kamal-Eldin A, Appelqvist LA. 1994. Variations in the composition of sterols, tocopherols and lignans in seed oils from four sesamum species. J. Am. Oil Chem. Soc. 71, 149-156.

Kamal-Eldin A, Andersson R. 1997. A multivariate study of the correlation between tocopherol content and fatty acid composition in vegetable oils. J. Am. Oil Chem. Soc. 74, 375-380.

Lalas S, Tsaknis J. 2002. Characterization of Moringa oleifera seed oil variety Periyakulam-1. J. Food Comp. Anal. 15, 65-77. 
Latif S, Anwar F. 2008. Quality assessment of Moringa concanensis seed oil extracted through solvent and aqueous-enzymatic techniques. Grasas Aceites 59, 69-75.

Manzoor M, Anwar F, lqbal T, Bhanger MI. 2007. Physicochemical characterization of Moringa concanensis seeds and seed oil. J. Am. Oil Chem. Soc. 84, 413419.

Namiki M. 2007. Nutraceutical functions of sesame: A Review. Cri. Rev. Food Sci. Nutr. 47, 651-673.

Ogunsina BS, Indira TN, Bhatnagar AS, Radha C, Debnath S, Gopala Krishna AG. 2011. Quality characteristics and stability of Moringa oleifera seed oil of Indian origin. J. Food Sci. Technol., DOI 10.1007/s13197-011-0519-5.

Paquot C, Havtfenne A (eds). 1987. IUPAC method No. 2.301. Standard methods for analysis of oils, fats and derivatives. International Union of Pure and Applied Chemistry, 7th edn. Blackwell, Oxford, pp. 174-182.

Rahman IMM, Barua S, Nazimuddin M, Begum ZA, Rahman MA, Hasegawa H. 2009. Physicochemical properties of Moringa oleifera Lam. seed oil of the indigenous-cultivar of Bangladesh. J. Food Lipids. 16, 540-553.
Ramachadran C, Peter KV, Gopalakrishnan PK. 1980. Drumstick (Moringa oleifera): A multipurpose Indian vegetable. Econ. Bot. 34, 276-283.

Sabir SM, Hayat I, Gardezi SDA. 2003. Estimation of sterols in edible fats and oils. Pak. J. Nutr. 2, 178181.

Sengupta A, Gupta MP. 1970. Studies on seed fat composition of Moringaceae family. Fette Seifen Anstrichm. 72, 6-10.

Siger A, Nogala-Kalucka M, Lampart-Szczapa E. 2008. The content and antioxidant activity of phenolic compounds in cold-pressed plant oils. J. Food Lipids. 15, 137-149.

Tsaknis J, Spiliotis V, Lalas S, Gergis V, Dourtoglou V. 1999. Quality changes of Moringa oleifera, variety Mbololo of Kenya, seed oil during frying. Grasas Aceites. 50, 37-48.

Taga MS, Miller EE, Pratt DE. 1984. Chia seeds as a source of natural lipid antioxidants. J. Am. Oil Chem. Soc. 61, 928-993.

Recibido: $11 / 1 / 13$ Aceptado: $17 / 6 / 13$ 